\section{Kastamonu Eğitim Dergisi Kastamonu Education Journal}

Mayıs 2019 Cilt:27 Sayı:3

kefdergi.kastamonu.edu.tr
Başvuru Tarihi/Received: 13.11.2017

Kabul Tarihi/Accepted: 26.06.2018

DOI: $10.24106 /$ kefdergi.2369

\title{
Yardım Davranışlarının Schadenfreude, Benlik Saygısı ve Benlik Tehdit Algısı Bakımından İncelenmesi
}

\section{Helping Behavior in Terms of Schadenfreude, Self-Esteem and Self- Threat}

\author{
Seda ERZí ${ }^{1}$
}

\section{Öz}

Bu çalışmanın amacı schadenfreude, sempati, benlik saygısının yardım davranışı bakımından incelenmesidir. Örneklem 179 kadın, 56 erkek olmak üzere 235 lisans öğrencisinden oluşmaktadır ( $M=20.21$ ). Benlik kıyaslaması ve hedef kişinin başına gelen kötü olaydaki sorumluluğu farklı senaryolar kullanılarak manipüle edilmiştir. Katılımcılar 4 farklı manipülasyon grubuna seçkisiz olarak atanmışlardır. Bu gruplar: yüksek başarıyüksek sorumluluk, yüksek başarı düşük sorumluluk, düşük başarı düşük sorumluluk, düşük başarı yüksek sorumluluk grupları olarak ayrılmaktadır. Yardım davranışı sorumluluk senaryosu ile bağıntılı olan bir soruyla ölçülmüştür. Bulgulara göre, yardım davranışının, schadenfreude ve sempati duyguları bakımından anlamlı düzeyde yordandığı görülmüştür. Bununla birlikte yardım etmeyi seçen ve seçmeyen katılımcılar arasında schadenfreude ve sempati duygusu bakımından anlamlı düzeyde farklıık bulunmuştur. Yapılan korelasyon analizi neticesinde schadenfreude, benlik kıyaslaması, benlik saygısı ve sempati arasında anlamlı ilişki bulunmuş; ancak yardım miktarı ile diğer değişkenler arasında anlamlı düzeyde ilişki bulunmamıştr. Bulgular ilgili literatür ışığında tartşııımıştır.

Anahtar Kelimeler: Benlik saygısı, yardım etme davranışı, schadenfreude

\section{Abstract}

The purpose of this study is to examine the links between schadenfreude, sympathy and self-esteem in terms of helping behavior. Sample consists of 179 female and 56 male undergraduates ( $M$ age $=20.21$ ). Self-comparison and the actor's responsibility from the misfortune are manipulated by different scenarios. Participants are randomly assigned to 4 different groups; high achiever-high responsibility, high achiever-low responsibility, low achiever-high responsibility, low achiever-low responsibility. Helping behavior is measured with a question which is related to responsibility scenario. Results show that decison of help is predicted by schadenfreude and sympathy significantly. There are several differences between those who choose to help the actor and who don't in terms of schadenfreude, sympathy. Correlations show that there are several relationships between self-esteem, self-comparison, schadenfreude and sympathy but there are no significant relationship between amount of help and the other measures. Results of the study are discussed within the light of literature.

Keywords: Helping behavior, schadenfreude, self-esteem

1. Maltepe Üniversitesi, İnsan ve Toplum Bilimleri Fakültesi, Psikoloji Bölümü, Psikoloji Anabilim Dalı, İstanbul, Türkiye; https://orcid.org/0000-0003-4450-158X Atıf / Citation: Erzi, S. (2019). Yardım davranışlarının schadenfreude, benlik saygısı ve benlik tehdit algısı bakımından incelenmesi.Kastamonu Education Journal, 27(3), 1015-1021. doi:10.24106/kefdergi.2369 


\section{Extended Summary}

\section{Introduction}

Schadenfreude" is a German word that expresses pleasure and enjoyment of someone else's sorrow or discomfort. In the literature, this concept is described as enjoying someone else's unhappiness (Feather, Wenzel and McKee, 2013). Studies have shown that low self-esteem and high self-threat are related to schadenfreude (Jung, 2017; Van Dijk et al, 2011). If the individual's self-esteem is low, individuals are more prone to feel self-threat and they feel more schadenfreude to the target person. In the emergence of the schadenfreude, target's responsibility about the misfortune is also important. (Smith, Powell, Combs and Schulz, 2009; Van Dijk et al., 2011). The relationship between helping behaviors and self-esteem is also supported by many findings in the literature (Laible, Carlo and Roesch, 2004; Zuffianò et al., 2014). The responsibility of the target about the misfortune is also important for the emergence of the helping behaviors (Lee, Winterich and Ross, 2014). The purpose of this study was to examine the helping behaviors in terms of self-esteem, self-threat, responsibility and schadenfreude. From this point of view, status of the target person was manipulated as high-achiever and low-achiever. Also target's responsibility about the misfortune was manipulated. In this context, individuals may feel schadenfreude about the target's misfortune. However, they may prefer to help the individual because his or her responsibility about the misfortune is low. In this study, helping behavior was measured by the answer given in the question "How long will you help the target person to study?" Helping is often measured by donating (Aquino and Redd, 2002; Lee, Winterich and Ross, 2014). In this study, however, it is desirable to measure how much time participants spend for helping the target. In the study conducted by Reed et al. (2007), helping was measured how much time the participants spent on helping. The primary hypothesis of the study was helping behavior will be explained significantly by schadenfreude, sympathy, self-esteem, self-esteem and the target's responsibility about the misfortune. The second hypothesis of the study was schadenfreude will be explained significantly by self-esteem and sympathy. Besides, it is expected that there will be a significant difference between helping groups in terms of schadenfreude and sympathy.

\section{Method}

Sample consists of 179 female and 56 male undergraduates ( $M$ age $=20.21$ ). Self-comparison and the target's responsibility about the misfortune were manipulated by different scenarios. Participants are randomly assigned to 4 different groups; high achiever high responsibility, high achiever low responsibility, low achiever high responsibility, low achiever low responsibility.

\section{Results and Discussion}

As a result, there was a significant relationship between the self-esteem of the individual and the schadenfreude. Self-threat and self-esteem were correlated as expected. Similarly, Jung (2017) showed that self-esteem increased with the increase of self-comparison. In this study, there was no significant relationship between helping behavior and responsibility, sympathy, and schadenfreude. However, there were some significant differences between helping groups in terms of schadenfreude. Also sympathy score of those who chose to help is significantly higher than those who do not. Similarly, Schulz, Rudolph, Tscharaktschiew, and Rudolph (2013) found that schadenfreude reduced sympathy and helping behavior. Logistic regression analysis has shown that the meaningful predictors of helping decision are only schadenfreude and sympathy. This result is consistent with the literature findings (Greitemeyer, Osswald and Brauer, 2010; Schulz, Rudolph, Tscharaktschiew \& Rudolph, 2013; Tscharaktschiew \& Rudolph, 2016). Schadenfreude was predicted significantly by self-esteem and self-threat among males. Low self-esteem and high self-threat revealed the schadenfreude. Similarly, Van Dijk, Koningsbruggen, Ouwerkerk and Wesseling (2011) measured individuals' emotions towards the high-achiever target. As a result of the research, they found that individuals with high self-esteem showed more sympathy towards high and low achiever. In this study, although the schadenfreude was felt, it was predicted that the charitable decision could change according to the target's responsibility about the misfortune. Nevertheless, the results showed that the target's responsibility was not a significant predictor of the helping behavior. On the other hand, self-esteem, self-perception and self-esteem were not significant predictors of helping behaviors only schadenfreude and sympathy were found to be significant predictors. This study had limitations in terms of measurement of helping. In future studies, it is thought that helping behavior can be measured by observation. Instead of asking how long the participants will hypothetically help, it is thought that the behavioral measures will contribute to obtain more significant findings. Another limitation is the use of scenarios. Although these scenarios reveal elements such as schadenfreude, self-threat, target's responsibility, participants can also be exposed to a voice recording where they can hear the voice of the target. 


\section{Giriş}

"Schadenfreude" başkasının üzüntüsünden ya da sıkıntısından keyif ve zevk alma durumunu ifade eden Almanca bir kelimedir. Literatürde bu kavram benzeri biçimde başkasının mutsuzluğundan keyif alma olarak belirtilmektedir (Feather, Wenzel ve McKee, 2013). Mutluluk, neşe gibi duygulara kıyasla bu duygunun ifade edilmesi ya da hissedildiğinin kabullenilmesi nahoş olarak düşünülebilmektedir (Jung, 2017). "Schadenfreude" kavramı, kişilerarası ilişkileri anlama bakımından önem taşımaktadır. Smith, Powell, Combs ve Schurtz (2009) tarafindan yapılan çalışmada, schadenfreude iç ve dış grup dinamikleri, benlik saygısı, bu duygunun hissedildiği bireyin olaydaki sorumluluğu gibi faktörlerle açıklanmaktadır. Yapılan çalışmalarda, benlik saygısı düşüklüğünün ve benlik tehdit algısının yüksekliğinin, bireylerin bu duyguyu hissetmeleriyle ilişkili olduğu belirtilmiştir (Jung, 2017; Van Dijk ve ark, 2011). Benlik saygısı ve schadenfreude arasındaki ilişkinin kaynağı bireylerin benlik saygısı düşük olduğunda, benlikleri ile ilgili tehdit algısının daha fazla olması, bu bağlamda da hedef kişiye daha fazla schadenfreude hissetmeleridir. Bu bağlamda hedef kişinin özellikleri schadenfreude hissedilebilmesi bakımından önem taşımaktadır. Schadenfreude duygusunun ortaya çıkmasında bireyin düştüğü durumdaki sorumluluğu da önem taşımaktadır. Hedef kişinin düştüğü olumsuz durumda, hedef kişinin sorumluluğunun az ya da çok olması da o kişiye karşı hissedilen schadenfreude duygusunu değiştirmektedir (Smith, Powell, Combs ve Schulz, 2009; Van Dijk ve ark, 2011). Bununla birlikte bu çalışmada yardım davranışı kişinin hedef senaryodaki bireye ne kadar zamanını ayıracağı ile ölçülmek istenmektedir. Yardım davranışları ile bireylerin benlik saygıları arasındaki ilişki literatürdeki pek çok bulguyla desteklenmektedir (Laible, Carlo and Roesch, 2004; Zuffianò ve ark, 2014 ). Yardım davranışlarının gerçekleşebilmesinde, yardım alacak kişinin olaydaki sorumluluğu da önem taşımaktadır (Lee, Winterich ve Ross, 2014). Bu çalışmanın amacı yardım davranışlarının, benlik saygısı, benlik tehdit algısı, sorumluluk algısı ve schadenfreude bakımından incelenmesidir. Van Dijk, Koningsbruggen, Ouwerkerk ve Wesseling (2011) tarafindan lisans öğrencileri ile yapılan çalışmada, benlik saygıları düşük olan bireylerin, daha fazla benlik tehdidi hissettikleri, bu bağlamda da daha fazla schadenfreude duygusu hissettikleri görülmüştür. Bu bağlamda, bireyler sosyal kıyaslama sonucunda, benliklerini tehdit altında hissettiklerinde, schadenfreude duygusunu daha fazla yaşamaktadırlar. Benlik saygısının yapılan çalışmalarda olumlu sosyal davranışlarla ve yardım davranışlarıyla ilişkili olduğu tespit edilmiştir. Zuffianò ve ark (2014) tarafindan genç yetişkinlerle yapılan boylamsal çalışmada, genç yetişkinlerin olumlu sosyal davranışlarının benlik saygıları ile ilişkili olduğu belirlenmiştir. Benlik saygısının yanında, yardımı alan kişinin olaydaki sorumluluğunun yardım davranışlarıyla ilişkilendirildiği belirtilmiştir. Lee ve ark (2014) tarafindan yapılan çalışmada yardım etme kararı verilen kişinin, olaydaki sorumluluğun yüksek olduğu durumlarda yapılan yardımın azaldığı görülmüştür. Yapılan çalışmalarda sorumluluk genellikle kişinin hak etme düzeyi başlığı altında incelenebilmekle birlikte, aynı zamanda kendi başına da incelenebilmektedir. Feather, Wenzel ve McKee (2013) tarafindan yapılan çaıışmada bireyin yaşadığı başarısızlıktaki sorumluluğunun yüksekliğinin, schadenfreude duygusu ile bağıntlı olduğu bulunmuştur. Yine aynı çalışmada, bireyin başarısını hak etme düzeyinin yüksekliği ile schadenfreude duygusunun negatif yönde ilişkili olduğu bulunmuştur. Bu bağlamda bireyin yaşadığı olumsuz durumdaki sorumluluğu, hem schadenfreude duygusunun hissedilmesinde hem de yardım davranışına karar verilmesinde etkilidir. Yapılan çalışmalarda schadenfreude duygusunun yardım davranışlarıyla negatif yönde ilişkili olduğu bulunmuştur, bu durumda bireye yardım etme kararının verilmesinde, sempati (acıma duygusu) aracı rol üstlenerek yardım kararının verilmesini sağlarken, schadenfreude yardımın gerçekleşmemesine neden olmaktadır (Schulz, Rudolph, Tscharaktschiew and Rudolph, 2013). Yapılan bazı çalışmalarda olumlu sosyal medya kullanımının özellikle bu davranışları teşvik eden oyunlar oynamanın empati duygusunu arttırırken, schadenfreude duygusunu azalttğı bulunmuştur (Greitemeyer, Osswald ve Brauer, 2010). Benzeri biçimde James, Kavanagh, Jonason, Chonody ve Scrutton (2014) tarafindan yapılan çalışmada, kişiliğin karanlık tarafları olarak alt çizilen, makyevelizm, psikopati ve narsisistik özelliklerin schadenfreude duygusu ile olumlu yönde ilişkili bulunduğu tespit edilmiştir. Porter, Bhanwer, Woodworth ve Black (2013) tarafindan yapılan çalışmada ise karanlık kişilik özelliklerine (makyevelizm, narsisizm) sahip bireylerin, daha fazla schadenfreude duygusu ifade ettikleri bulunmuştur. Bu açıdan değerlendirildiğinde, schadenfreude duygusunun genellikle yardım davranışları yerine, anti sosyal davranışlarla iliş̧ilendirildiği görülmektedir. Buradan hareketle bu çalışmada, yüksek düzeyde başarılı ve düşük düzeyde başarılı iki farklı grup senaryolarla manipüle edilecektir. Bunun yanı sıra hedef bireylerin olaydaki sorumluluk düzeyleri de manipüle edilecektir. Bu bağlamda bireyleri düşük düzeyde başarılı hedefi değerlendirirken benlik tehdit algıları az olsa da benlik saygıları düşük olduğu için, hedefin başına gelen kötü durumda schadenfreude hissedebilirler. Buna karşın, bireyin olaydaki sorumluluğu düşük olduğu için ona yardım etmeyi tercih edebilirler. Bu çalışmada yardım davranışı "hedef kişinin ders çalışmasına ne kadar süre yardım edersiniz" sorusuna verilen cevapla ölçülmüştür. Yapılan çalışmalarda yardım davranışı genellikle bağış yapma gibi unsurlarla ölçülmektedir (Aquino ve Redd, 2002; Lee, Winterich ve Ross, 2014). Ancak bu çalışmada, katlımcıların zamanlarının ne kadarını yardım etmeye harcayacakları ölçülmek istenmiştir. Reed ve ark (2007) tarafindan yapılan çalışmada da benzeri biçimde katılımcıların, hedef kişiye yardım etme süresi ölçülmüştür. Çalışmanın birinci hipotezi, yardım davranışının, schadenfreude, sempati, benlik kıyaslaması, benlik 
saygısı ve hedef kişinin olaydaki sorumluluğu bakımından anlamlı düzeyde yordanmasıdır. Çalışmanın ikinci hipotezi schadenfreude duygusunun, benlik saygısı ve benlik kıyaslaması bakımından anlamlı düzeyde yordanmasıdır. Bunun yanı sıra, yardım etmeyi tercih eden ve etmeyen gruplar arasında schadenfreude ve sempati duygusu bakımından anlamlı düzeyde farklılık olması beklenmektedir.

\section{Yöntem}

\section{Katilımcilar}

Çalışmaya 179 kadın 56 erkek olmak üzere toplamda 235 lisans öğrencisi katılmıştır (M=20.21). Katılımcılara uygun örnekleme yoluyla ulaşılmıştır. Katılımcıların annelerinin \%33.6'sı ilkokul, \%17.6'sı ortaokul, \%31.6'sı lise mezunu, \%14.3'ü lisans mezunudur. Katlımcıların babalarının \%17.2'si ilkokul, \%19.3'ü ortaokul, \%32.8'i lise mezunu, \%26.2'si lisans mezunudur. Katılımcıların \%81.2'si şehir, büyük şehir ve metropolde doğmuştur. Katılımcıların \%83.8'i şehir, büyük şehir ve metropolde yaşamının büyük çoğunluğunu geçirmiştir. Gelir durumuna bakıldığında katılımcıların \%82.3'ünün aylık geliri 3000 TL ve üzeridir. Bu bağlamda çalışmanın katılımcılarının orta üst sosyo-ekonomik düzeyde olduğu düşünülmektedir.

\section{Veri Toplama Araçları}

\section{Rosenberg Benlik Saygısı Ölçeği}

Bu ölçek Rosenberg (1965) tarafindan geliştirilmiştir. Benlik saygısı alt ölçeği 4 lü likert tipi 10 maddeden oluşmaktadır (aktaran Robins, Hendin ve Trzesniewski, 2001). Bu çalışmadaki cronbach alpha güvenirlik katsayısı .83 olarak hesaplanmıştir.

\section{Senaryolar}

Bu bölümde, hedef bireyin başarı düzeyine göre düşük ve yüksek olmak üzere iki farklı senaryo kullanılmıştır. Yaşanılan olumsuz durumdaki sorumluluğun düşük ve yüksek düzeyde olduğu iki adet senaryo verilmiştir (bkz:EK A). Senaryolar, Jung (2017) tarafindan yapılan çalışmada kullanılan senaryolardan esinlenilerek oluşturulmuştur. Hedef kişinin başarı durumuyla ilgili iki farklı senaryo farklı gruplar tarafindan okunduktan sonra, katılımcılar benlik tehdit algısına dair üç soruyu cevaplamıştır. Soruların cronbach alpha güvenirlik katsayısı .63 olarak hesaplanmıştır. Yaşanılan olumsuz durumdaki sorumluluğun düşük ve yüksek düzeyde olduğu senaryoların ardından var olan manipülasyonun işleyip işlemediğini anlamak amacıyla katılımcılara sorumluluk ve schadenfreude duygusu hissetme düzeyleri ile ilgili 6 soru sorulmuştur. Soruların cronbach alpha güvenirlik katsayısı .64 olarak hesaplanmıştır.

\section{Yardım Davranışı}

Çalışmada yardım davranışı, katılımcıların hedef kişiye ne kadar süre yardım edeceklerini belirtmeleri yoluyla ölçülecektir.

\section{İşlem}

Katılımcılar ilk etapta altmışar kişiden oluşan 4 farklı manipülasyon grubuna seçkisiz olarak atanmışlardır. Tüm gruplarda yer alan katılımcılar, ilk olarak benlik saygısı ölçeğini cevaplamışlardır. Bunun ardından 4 grup çeşitli senaryolar okumuştur. İlk grup hedef kişinin başarı düzeyinin ve yaşanılan olumsuz durumdaki sorumluluğunun yüksek düzeyde olduğu senaryoyu okumuştur. İkinci grup, hedef kişinin başarı düzeyinin yüksek olduğu ancak yaşanılan olumsuz durumdaki sorumluluğunun düşük düzeyde olduğu senaryoyu okumuştur. Üçüncü grup, hedef kişinin başarı düzeyinin ve yaşanılan olumsuz durumdaki sorumluluğunun düşük düzeyde olduğu senaryoyu okumuştur. Dördüncü grup, hedef kişinin başarı düzeyinin düşük olduğu ancak yaşanılan olumsuz durumdaki sorumluluğunun yüksek düzeyde olduğu senaryoyu okumuştur. Katılımcılar, hedef kişinin başarı düzeyi ile ilgili senaryoyu okuduktan sonra benlik tehdit algısı ile ilgili soruları cevaplamışlardır. Bunun ardından, hedef kişinin yaşanılan olumsuz durumdaki sorumluluğu ile ilgili senaryoyu okuyan katılımcılar, sorumluluk düzeyini, hedef kişiye karşı hissettikleri schadenfreude ve sempati duygusunu değerlendirmişlerdir. Katılımcılar son olarak hedef kişiye ne kadar süre yardım edeceklerine ilişkin soruyu yanıtlamışlardır.

\section{Bulgular}

Benlik saygısı ve benlik kıyaslaması anlamlı derecede ilişkili bulunmuştur $(r(233)=.23 p<.01)$. Kişinin benlik saygısı azaldıkça benlik tehdidi artmaktadır. Ayrıca schadenfreude ve benlik saygısı arasında anlamlı bir ilişki vardır ( $r$ (239) = - . 18 p <.01). Kişinin benlik saygısı düştükçe schadenfreude hissetme durumu artmaktadır. Kadınların benlik kıyaslaması 
ve benlik saygısı arasında anlamlı düzeyde ilişki bulunmuştur $(r(168)=.26 p<.01)$. Hedef kişinin olaydaki sorumluluğu ile ona yönelik hissedilen schadenfreude arasında anlamlı ilişki tespit edilmiștir ( $r(168)=.16 p<.05)$. Hedef kişinin başına gelen kötü olaydaki sorumluluğu arttkça ona yönelik schadenfreude duygusu da artmaktadır. Erkeklerin benlik saygısı ve schadenfreude arasında anlamlı bir ilişki bulunmuştur $(r(55)=.37 p<0.01)$. Erkeklerin, benlik saygısı düştükçe schadenfreude duygusu artmaktadır. Schadenfreude ve sempati ile anlamlı bir ilişki vardır $(r(55)=-.28 p<.05)$. Hedef kişinin bulunduğu duruma yönelik sempati (acıma) duygusu arttikça schadenfreude duygusu azalmıştr. Benlik tehdit algısı bakımından erkekler ve kadınlar arasında anlamlı farklılık bulunmuştur ( $\mathrm{t}(230)=-286 \mathrm{p}<.01$ ). Erkekler kadınlardan anlamlı düzeyde derecede yüksek puan almıştı. Erkekler schadenfreude bakımından da kadınlardan anlamlı düzeyde daha yüksek puan almıştı $(\mathrm{t}(230)=-3.45 \mathrm{p}<.01$ ). Yardım grupları arasında sadece schadenfreude açısından anlamlı bir farklılık bulunmuştur (t $(237)=-3.48 \mathrm{p}<0.01$ ). Yardım etmeyi tercih eden katlımcıların schadenfreude puanı yardım etmeyenlerden anlamlı düzeyde düşüktür. Kadınlar arasında yardım etmeyi seçenlerin schadenfreude puanı yardım etmeyenlerden anlamlı düzeyde düşüktür $(t(173)=-2.53 p<.05)$. Benzeri biçimde yardım etmeyi seçen kadınların sempati duygusu puanı etmeyenlerden anlamlı düzeyde yüksektir ( $\mathrm{t}(173)=5.18 \mathrm{p}<.001)$. Erkekler arasında yardım etmeyi seçenlerin schadenfreude puanı yardım etmeyenlerden anlamlı düzeyde düşüktür $(t(173)=-2,72 p$ <.01). Yardım miktarı ile schadenfreude, sempati, benlik karşılaştırması, benlik saygısı ve sorumluluk puanı arasında anlamlı bir korelasyon tespit edilmemiştir. Doğrusal regresyon analizi uygulanarak erkeklerin benlik saygısı ve benlik kıyaslama puanının birlikte schadenfreude varyansını ne düzeyde açıkladığı tespit edilmiştir. Elde edilen sonuçlara göre schadenfreude, benlik saygısı ve kendilik karşılaştırması bakımından \% 13.5 oranında açıklanmıştr. Ancak modelde yalnızca benlik saygısı anlamlıdır ( $p=.008)$. Daha önce belirtildiği gibi yardım etme miktarı ile değişkenler arasında anlamlı bir korelasyon tespit edilememiştir. Ancak yardım etme kararının, schadenfreude, benlik kıyaslaması, benlik saygısı, sorumluluk, sempati tarafindan ne düzeyde açıklandığını tespit etmek amacıyla lojistik regresyon analizi uygulanmıştır. Yapılan uygunluk testi neticesinde modelin uygun ve anlamlı olduğu görülmüştür $\left(x^{2}=24.25, p<.001\right.$ ve df = 5). Nagelkerke $r^{2}$ değeri .21 olarak bulunmuştur. Söz konusu değişkenler yardım kararını \%21 oranında açıklamaktadır. Modelin tahmin etme gücü \% 89.4 olarak bulunmuştur. Wald kriteri, yalnızca schadenfreude $(p=.006)$ ve sempati $(p=.003)$ değişkenlerinin modele istatistiksel olarak anlamlı önemli bir katkı yaptığını göstermiştir.

\section{Sonuçlar}

Yapılan analizler neticesinde bireyin benlik saygısı düşüklüğü ve schadenfreude arasında anlamlı ilişki bulunmuştur. Bireyin, benlik saygısının düşük olması, aynı zamanda benlik tehdit algısını daha fazla hissetmesine ve benlik kıyaslaması yapmasına bu bağlamda schadenfreude duygusunun da artmasına neden olmaktadır. Hedef kişi ile ilgili bilgiler, benlik saygısı düşük katlımcılarda daha fazla benlik tehdit algısı yaratmakta, bu durum da daha fazla schadenfreude hissedilmesine yol açmaktadır. Yapılan çalışmalarda, düşük benlik saygısı ve benlik saygısı yüksek algılamanın schadenfreude ile ilişkili olduğu gösterilmiştir (Jung, 2017; Van Dijk ve ark., 2011). Kendini karşılaştırma ve benlik saygısı da beklendiği gibi birbiriyle ilişkilidir. Benzer şekilde Jung (2017), benlik kıyaslamanın artmasıyla kendilik tehdidinin arttı̆ını ve bu durumun kişinin benlik saygısı ile ilişkili olduğunu göstermiştir. Tüm örneklemde schadenfreude ile hedef kişinin olaydaki sorumluluğu arasında anlamlı ilişki tespit edilmemesine karşın, kadınlarda hedef kişinin olaydaki sorumluluğu arttkça ona karşı hissedilen schadenfreude duygusunun arttğı gözlemlenmiştir. Benzer şekilde Tscharaktschiew ve Rudolph (2016) çalışmasında, hedef kişinin durumundan sorumlu olduğu zaman schadenfreude'nin arttı̆̆ını tespit etmiştir. Lee, Winterich ve Ross (2014) yaptığı çalışmada, hedef kişinin olaydaki sorumluluğu arttıkça yardım davranışının azalacağını tespit etmiştir. Ancak bu çalışmada yardım miktarının diğer değişkenlerle anlamlı düzeyde iliş̧isi tespit edilememiştir. Bu bakımından hedef kişinin olaydaki sorumluluğunun artmasının, yardım davranışıyla olan ilişkisi ya da schadenfreude duygusunun yardım davranışıla olan ilişkisi tespit edilememiştir. Bu çalışmada yardım davranışı, katılımcıların hedef kişiye ne kadar süre yardım edeceklerini belirtmeleriyle ölçülmüştür. Benzeri bir ölçüm, Reed ve ark (2007) tarafindan kullanılmıştır. Fakat bu çalışmada, yardım davranışı ile hedef kişinin olaydaki sorumluluğu, sempati, schadenfreude arasında anlamlı ilişki tespit edilememiştir. Ancak, yardım etmeyi tercih eden ve etmeyen bireyler arasında bazı önemli farklııklar bulunmuştur. Yardım etmeyi tercih eden grubun schadenfreude puanının yardım etmeyi tercih etmeyenlerden anlamlı düzeyde düşük olduğu bulgulanırken; sempati duygusu bakımından tam aksine bir bulgu elde edilmiştir. Yardım eden bireylerin sempati puanı etmeyenlerden anlamlı düzeyde yüksektir. Benzeri biçimde Schulz, Rudolph, Tscharaktschiew ve Rudolph (2013), sempati duygusunun yardım davranışını arttrırken, schadenfreude duygusunun bu türden davranışları azalttğını bulmuştur. Greitemeyer, Osswald ve Brauer (2010), sosyal oyun oynamanın empatiyi geliştirdiğini ve ayrıca şans oyunu oranının düştüğünü göstermiştir. Ayrıca antisosyal davranışların schadenfreude duyguları ile bağlantılı olduğu bulunmuştur. Bu bağlamda bulgular literatürdeki çalışmalarla paralellik göstermektedir. Yardım davranışında bulunanlarda sempati duygusu ağır basarken, bulunmayanlarda schadenfreude daha etkin gözükmektedir. Bununla bağıntılı olarak, lojistik regresyon analizi sonucunda yardım etme kararının anlamlı yordayıcılarının yal- 
nızca schadenfreude ve sempati olduğu görülmüştür. Bu sonuç, literatür bulguları ile tutarlıdır (Greitemeyer, Osswald ve Brauer, 2010; Schulz, Rudolph, Tscharaktschiew ve Rudolph, 2013; Tscharaktschiew ve Rudolph, 2016). Erkeklerde, schadenfreude duygusu, benlik saygısı ve benlik kıyaslaması tarafindan anlamlı düzeyde yordanmıştr. Bireydeki düşük benlik saygısı, hedef kişinin ortaya çıkması ve benlik kıyaslaması neticesinde benlik tehdidi yaratması schadenfreude duygusunu ortaya çıkarmaktadır. Benzer şekilde Van Dijk, Koningsbruggen, Ouwerkerk ve Wesseling (2011) bireylerin yüksek başarı düzeyinde hedef kişiye karşı duygularını ölçmüşlerdir. Araştırma sonucunda, benlik saygısı yüksek olan bireylerin daha fazla sempati duygusu gösterdiğini, aksinde ise schadenfreude duygusunun yükseldiğini bulmuşlardır. Smith, Powell, Combs ve Schulz (2009) çalışmasında da, schadenfreude duygusu benlik saygısı ile anlamlı düzeyde açıklanmıştır. Bu çalışmada, schadenfreude hissedilmesine rağmen, yardım kararının hedef kişinin sorumluluğuna göre değişebileceği öngörülmüştür. Bununla birlikte, sonuçlar, hedef kişinin, olaydaki sorumluluğunun yardım davranışını açıklamada anlamlı bir yordayıcı olmadı̆̆ını göstermiştir. Öte yandan, benlik saygısı, benlik tehdit algısı ve benlik kıyaslamasının da, yardım davranışının anlamlı yordayıcıları olmadığı, yalnızca schadenfreude ve sempati duygusunun yardım kararını anlamlı düzeyde açıkladığı görülmüştür.

\section{5. Öneriler}

Bu çalışmada yardım miktarının ölçülme biçimi bakımından bir sınırlılık ortaya koyduğu düşünülmektedir. Katılımcıların hedef kişiye ne kadar süre yardım edeceklerini belirttikleri süre bakımından ölçen yardım miktarı değişkeni diğer değişkenlerle anlamlı düzeyde ilişkili bulunamamıştır. İleride yapılacak çalışmalarda yardım davranışının, daha deneysel bir yöntemle ölçülmesinin anlamlı sonuçlar verme yönünde katkı sağlayacağı düşünülmektedir. Bununla birlikte katılımcıların yardım etme kapsamında ödeyeceği bedelin daha fazla olacağı türde yardım davranışı ölçümünün yapılmasının da yararlı olabileceği düşünülmektedir. Katılımcılara varsayımsal olarak ne kadar süre yardım edeceklerinin sorulması yerine, yardım ederken bedel ödeyebilecekleri davranışsal ölçümlerin daha anlamlı bulgular elde edilmesine katkı sağlayacağı düşünülmektedir. Bir diğer sınırlılık da, çalışmada hedef kişinin özelliklerine ve başına gelen hadiseye dair senaryolar kullanılmasıdır. Her ne kadar bu senaryolar, schadenfreude, benlik tehdit algısı, hedef kişinin olaydaki sorumluluğu gibi unsurları ortaya çıkarmış olsa da, katılımcıların hedef kişinin sesini duyabildikleri bir ses kaydı ya da görüntüsüne de maruz kalabilecekleri bir video kaydının, inandırıcılık işlevini daha da arttıracağı düşünülmektedir. Örneğin Schulz ve ark (2013) tarafindan yapılan çalışmada, çocuklara hedef kişinin içine düştüğü durum, öncesinde ve sonrasında yaptıkları görsel olarak resimler yoluyla anlatılmıştır. Bu ve benzeri yöntemlerin ilerideki çalışmalarda kullanılmasının yerinde olacağı düşünülmektedir.

\section{KAYNAKÇA}

Aquino, K., \& Reed II, A. (2002). The self-importance of moral identity. Journal of personality and social psychology, 83(6), 14-23.

Feather, N. T., Wenzel, M., \& McKee, I. R. (2013). Integrating multiple perspectives on schadenfreude: The role of deservingness and emotions. Motivation and Emotion, 37(3), 574-585.

Greitemeyer, T., Osswald, S., \& Brauer, M. (2010). Playing prosocial video games increases empathy and decreases schadenfreude. Emotion, 10, 796-802.

James, S., Kavanagh, P. S., Jonason, P. K., Chonody, J. M., \& Scrutton, H. E. (2014). The Dark Triad, schadenfreude, and sensational interests: Dark personalities, dark emotions, and dark behaviors. Personality and Individual Differences, 68, 211-216.

Jung, K. (2017). Happiness as an additional antecedent of schadenfreude. The Journal of Positive Psychology, 12(2), $186-196$.

Laible, D. J., Carlo, G., \& Roesch, S. C. (2004). Pathways to self-esteem in late adolescence: The role of parent and peer attachment, empathy, and social behaviours. Journal of adolescence, 27(6), 703-716.

Lee, S., Winterich, K. P., \& Ross, W. T. (2014). I'm moral, but I won't help you: The distinct roles of empathy and justice in donations. Journal of Consumer Research, 41(3), 678-696.

Porter, S., Bhanwer, A., Woodworth, M., \& Black, P. J. (2013). Soldiers of misfortune: An examination of the Dark Triad and the experience of schadenfreude. Personality and Individual Differences, 67, 1-5.

Reed, A., Aquino, K., \& Levy, E. (2007). Moral identity and judgments of charitable behaviors. Journal of Marketing, 71(1), $178-193$.

Robins, R. W., Hendin, H. M., \& Trzesniewski, K. H. (2001). Measuring global self-esteem: Construct validation of a single-item measure and the Rosenberg Self-Esteem Scale. Personality and social psychology bulletin, 27(2), 151-161.

Schulz, K., Rudolph, A., Tscharaktschiew, N., \& Rudolph, U. (2013). Daniel has fallen into a muddy puddle-Schadenfreude or sympathy?. British Journal of Developmental Psychology, 31(4), 363-378.

Smith, R. H., Powell, C. A., Combs, D. J., \& Schulz, D. R. (2009). Exploring the when and why of schadenfreude. Social and Personality Psychology Compass, 3(4), 530-546. 
Tscharaktschiew, N., \& Rudolph, U. (2016). The who and whom of help giving: An attributional model integrating the help giver and the help recipient. European Journal of Social Psychology, 46 (1), 90-109.

Van Dijk, W. W., van Koningsbruggen, G. M., Ouwerkerk, J. W., \& Wesseling, Y. M. (2011). Self-esteem, self-affirmation, and schadenfreude. Emotion, 11(6), 14-45.

Van Dijk, W. W., Ouwerkerk, J. W., van Koningsbruggen, G. M., \& Wesseling, Y. M. (2012). "So You Wanna Be a Pop Star?”: Schadenfreude Following Another's Misfortune on TV. Basic and Applied Social Psychology, 34(2), 168-174.

Zuffianò, A., Eisenberg, N., Alessandri, G., Luengo Kanacri, B. P., Pastorelli, C., Milioni, M., \& Caprara, G. V. (2014). The Relation of ProSociality to Self-Esteem: The Mediational Role of Quality of Friendships. Journal of Personality, 84 (1), 59-70.

\section{EK A}

Yüksek düzeyde başarı senaryosu: Aynı okulda öğrenim gördüğünüz bir tanıdığınız var. Bu kişi ekonomik durumu oldukça iyi bir aileden geliyor. Aynı zamanda akademik anlamda oldukça başarılı ve yüksek bir not ortalaması var. Bu kişi spor konusunda da oldukça başarılı, lisanlı bir yüzücü ve madalyaları var. Aynı zamanda çok çekici bir sevgilisi var.

Düşük düzey başarı senaryosu: Aynı okulda öğrenim gördüğünüz bir tanıdığınız var. Bu kişinin ailesi düşük gelir düzeyine sahip. Akademik anlamda başarılı değil, notları oldukça düşük. Spor konusunda hiç becerikli değil.

Sorumluluk yüksek: Aynı okulda öğrenim gördüğünüz bu kişi, alkollü araç kullandığı için kaza yapıyor. Herhangi bir yaralanma söz konusu olmuyor. Ancak arabası ciddi biçimde hasar görüyor. Bunun ardından sevgilisi onu terk ediyor. Ailesi de ona maddi anlamda yardımcı olmuyor ve sert tepki gösteriyor. Arabanın tamiri ile uğraşırken arkadaşınız tek bir dersten bütünlemeye kalıyor.

Sorumluluk düşük: Aynı okulda öğrenim gördüğünüz bu kişi, arkadaşının aracını kullanırken kırmızı ışıkta trafik kurallarına uygun olarak duruyor. Ancak arkasındaki araç ona çarpıyor. Herhangi bir yaralanma söz konusu olmuyor. Ancak araba ciddi biçimde hasar görüyor. Arabanın tamiri ile uğraşırken arkadaşınız tek bir dersten bütünlemeye kalıyor.

Sorumluluk Soruları: Bu kişinin sınava girememesindeki sorumluluğunun ne kadar olduğunu düşünüyorsunuz? Schadenfreude Soruları: 1) Kendimi biraz da olsa mutlu hissediyorum. 2)Kendimi tatmin olmuş hissediyorum. 3)Kendimi gülümsemekten alıkoyamıyorum. 4) Kendimi iyi hissediyorum. 